\title{
Letramentos acadêmicos e sujeitos discursivos: dialogia, alteridade e negociação sobre a escrita
}

\author{
Eliane A. Pasquotte-Vieira*
}

\section{Resumo}

A partir de um estudo de caso, este artigo propõe reflexões acerca da integração dos sujeitos a práticas letradas acadêmicas, considerando os diálogos ocorridos entre uma mestranda e os professores da banca de exame de qualificação de sua dissertação de mestrado. O objetivo é investigar os modos como a mestranda vai (re)significando práticas acadêmico-científicas de escrita e se (re)posicionando como um sujeito discursivo a partir do próprio processo dialógico - e, portanto, de negociação - que ocorre em torno da Introdução de sua dissertação. Como base teórico-metodológica, a perspectiva linguístico-discursiva bakhtiniana alia-se à abordagem etnográfica dos Letramentos Acadêmicos de modo a conceber um estudo de viés etnográfico-linguístico. A metodologia de geração de registros, seleção e aproximação de dados baseia-se no que Lillis (2008) tem concebido como "história do texto", ou seja, a consideração de dados de diferentes naturezas que estão ao redor do texto e que, somados ao próprio texto, contribuem para a compreensão de práticas acadêmicas de escrita e seu processo de significação para os sujeitos.

Palavras-chave: Letramentos Acadêmicos. Gêneros Acadêmicos. Escrita Acadêmica. Redação Científica. Etnografia Linguística.

\section{Introdução}

Este $\operatorname{artigo~}^{1}$ objetiva contribuir com as discussões sobre a integração dos sujeitos a práticas letradas acadêmicas com base em um estudo de caso cujas reflexões recaem sobre os modos como uma mestranda vai (re)significando práticas acadêmico-científicas de escrita e se (re)posicionando como sujeito discursivo a partir do processo dialógico que ocorre durante o evento de seu exame de qualificação de mestrado e segundo as relações de poder ali constituídas. Para isso, este estudo é desenvolvido sob a perspectiva discursiva das proposições teóricas de Bakhtin

Recebido: 10/08/2014 - Aprovado: 15/12/2014

http://dx.doi.org/10.5335/rep.v22i1.5197

Doutora em Linguística Aplicada pelo Programa de Pós-Graduação do Instituto dos Estudos de Linguagem (IEL-Unicamp). Integrante do Grupo de Pesquisa CNPq, processo 140567/2010-0. E-mail: elianepasquottevieira@gmail.com 
(2006 [1929-1930]; 2003 [1952-1953]) sobre enunciação, dialogismo, gênero discursivo e, consequentemente, sobre a relação sujeito e linguagem como um fenômeno social, histórico e essencialmente dinâmico. Somados ao enfoque discursivo, estão os aportes teóricos dos "Letramentos Acadêmicos" (LEA; STREET, 2006, 1998; LILLIS, 2008, 2003, 1999; STREET, 2010, 2009), desenvolvidos à luz de estudos socioculturais de cunho etnográfico que levam a refletir sobre a integração dos sujeitos a práticas letradas acadêmicas em meio a contextos específicos de discussões sobre escrita, interlocuções e relações de poder. A aliança entre a perspectiva enunciativo-dialógica bakhtiniana e o viés etnográfico dos Letramentos Acadêmicos permite a discussão não apenas sobre os textos produzidos, mas, também, sobre o próprio processo dialógico-discursivo que constrói os sentidos dos sujeitos sobre práticas letradas acadêmicas.

O caráter dialógico dos enunciados coloca as relações entre sujeito e linguagem em outro lugar que não o da singular habilidade em usar as regras gramaticais da norma padrão ou em desenvolver as características composicionais e organizacionais dos gêneros. Segundo Bakhtin/Voloshinov (2006), as formas de enunciação estão submetidas a uma hierarquia existente nas relações sociais, e isso leva necessariamente a refletir sobre "a importância incomensurável do componente hierárquico no processo de interação verbal, a influência poderosa que exerce a organização hierarquizada das relações sociais sobre as formas de enunciação" (BAKHTIN/VOLOSHINOV, 2006, p. 42). Quando se considera práticas de escrita existentes nas esferas da atividade acadêmica, sejam para realizar tarefas de disciplinas, de defesa de grau ou de publicações de caráter acadêmico-científico, esse princípio enunciativo induz a repensar o processo de integração dos graduandos e pós-graduandos a práticas acadêmicas de escrita à luz de questões discursivas que envolvem a enunciação dialógica, ou seja, sem resumi-lo apenas ao ensino de um conjunto de habilidades de escrita e, por vezes, relacionadas a características do gênero textual ou da socialização da cultura acadêmica.

Essas questões, no entanto, permanecem obscurecidas em decorrência da maneira como o conceito de letramento ainda se edifica como um fenômeno singular, situado apenas no período que compreende o Ensino Fundamental e Médio e relacionado ao domínio de um conjunto de habilidades e competências sobre a leitura e a escrita. Dessa crença, constrói-se o pressuposto de que bastaria aos estudantes universitários transferirem seu conhecimento para todas as práticas letradas, em qualquer situação e gênero demandados, ou seja, acredita-se que seria suficiente se espelharem única e completamente em suas práticas letradas antecedentes. Mas se, na universidade, há outras práticas, outros gêneros, outros interlocutores, outras relações de poder, outras situações de produção e circulação dos textos, então, 
isso implica renegar o mito do espelhamento sobre a escrita escolar e repensar o que a universidade precisa fazer para a integração dos sujeitos às novas situações de escrita. Do ponto de vista dos Letramentos Acadêmicos, o fato de as práticas sociais letradas serem situadas conduz à ideia de que não é possível ao aluno chegar "pronto" à universidade, assim como, do ponto de vista bakhtiniano, esse "acabamento" não poderia ocorrer previamente aos posicionamentos sociais e históricos ocupados pelo sujeito discursivo.

Na contramão dessa visão sobre a multiplicidade de letramentos e a necessidade de aprendizagem sobre as práticas letradas com as quais não estamos familiarizados, tem se acentuado, no Brasil, o discurso do déficit e do fracasso sobre os alunos "não tradicionais". Esse é um termo utilizado por Lillis (1999) ao se referir ao contexto britânico, cujas vagas têm sido historicamente reservadas para classes economicamente privilegiadas e, somente em tempos mais recentes, tiveram o acesso ampliado para incluir alunos de grupos sociais anteriormente excluídos. Da mesma maneira, no Brasil, esse discurso tem recaído particularmente sobre alunos oriundos de grupos sociais que antes não tinham acesso à escolarização básica e, hoje, em decorrência de políticas educacionais que estão expandindo o acesso ao Ensino Superior, chegam à universidade depois de terem frequentado escolas públicas, cuja carência do ensino fortalece a ideia de que as dificuldades de escrita em âmbito acadêmico estariam localizadas essencialmente entre os "não tradicionais", e a precariedade do letramento escolar seria, por si só, a responsável pelos obstáculos que o estudante teria ao escrever na universidade.

Estudos realizados por Lea e Street $(1998,2006)$, baseados em pesquisas realizadas em diversas universidades do Reino Unido, apontam que, em decorrência desse discurso do déficit, a integração dos sujeitos a práticas letradas tem encontrado entraves em decorrência de modelos de letramentos não apenas capazes de dificultar esse processo, mas, também, de contribuírem para o fracasso. Por assumir a escrita como habilidade técnica e objetivar o "conserto" dos problemas, geralmente, de ordem textual e gramatical, os autores denominaram uma dessas perspectivas como modelo de habilidades. Outro modelo de letramento criticado pelos autores é o da socialização acadêmica por tomar a escrita como um meio transparente de representação e centrar-se na tarefa de inculcar aos alunos a cultura da academia, tida como supostamente homogênea. Nesses modelos, os autores criticam o pressuposto de déficit da escrita dos alunos e propõem um terceiro modelo para a integração dos sujeitos a práticas letradas acadêmicas: o modelo dos letramentos acadêmicos.

Estreitamente aliada aos Novos Estudos do Letramento (NLS), essa abordagem parte do conceito de letramentos como práticas sociais situadas e, além de 
incorporar os modelos de habilidades de estudos e socialização acadêmica, também tem como perspectiva a necessidade de discussão e negociação para a integração dos sujeitos aos novos processos de escrita - o que transpõe a perspectiva do déficit. Fundamentado em aportes teóricos advindos de campos disciplinares e subcampos como os NLS, a Linguística Aplicada, a Sociolinguística, a Análise Crítica do Discurso, a Antropologia, as Teorias Socioculturais e a História da Educação, esse modelo busca discutir as práticas de letramentos envolvidas em questões epistemológicas complexas, dinâmicas e situadas em processos sociais em que se instalam as relações de poder.

\section{A “história do texto" como viés etnográfico-linguístico}

A aliança entre a linguística e a etnografia tem favorecido uma série de pesquisas sobre sociedade, cultura e linguagem e, entre elas, aquelas que se tornaram conhecidas como etnografia linguística. De acordo com Rampton et al. (2004), a etnografia linguística está relacionada a pesquisas que partem do princípio de que a linguagem e o mundo social moldam-se um ao outro. Assim, os mecanismos e as dinâmicas desses processos podem ser entendidos por meio de uma análise detalhada do uso da linguagem e da construção de significados nas atividades cotidianas. Dessa maneira, reúnem conhecimentos e metodologias de linguística e de etnografia com o objetivo de melhor compreender os sentidos das práticas de linguagem em determinadas instâncias e segundo os contextos sociais e culturais particulares em que essas práticas se inserem.

$\mathrm{O}$ viés etnográfico-linguístico proposto pelo presente trabalho diz respeito à abordagem teórico-metodológica utilizada para a geração de registros, assim como para a seleção e aproximação de dados segundo o que Lillis (2008) conceitua como "história do texto", ou seja, a consideração de dados que estão ao redor do texto e que, somados ao próprio texto, contribuem para a compreensão de práticas escritas acadêmicas e seu processo de significação para os sujeitos. De acordo com a proposta específica da autora, a etnografia linguística, como teoria, leva a uma relação de texto e contexto de forma não dicotômica e, com isso, é capaz de ampliar a visão sobre o material a ser analisado mantendo, ao mesmo tempo, os olhos sobre o linguístico e sobre outros elementos que envolvem as práticas socioculturais em torno dos textos. Com base nas informações obtidas pelos diálogos em torno do texto, é possível explorar o que está envolvido na escrita acadêmica a partir de situações reais de escrita e do ponto de vista dos sujeitos, sejam eles os próprios escritores (alunos ou profissonais) ou professores, orientadores, pareceristas, entre outros. Nessa abordagem, o olhar do pesquisador se move claramente para além do texto, 
buscando informações sobre o contexto que o envolve, embora o texto continue compondo um objeto fundamental à análise.

No caso do presente estudo, esse contexto está nos registros gerados por intermédio de um evento de exame de qualificação de dissertação de mestrado em Agricultura e Ambiente, realizado em uma universidade pública no Estado de São Paulo que possui campi em diferentes cidades do interior e atividades nas áreas de ensino, pesquisa e extensão, com projetos de pesquisas desenvolvidos por professores e alunos de graduação e pós-graduação, com mestrados, doutorados e especializações. A partir disso, a história do texto a ser investigada diz respeito aos diálogos orais e escritos ocorridos entre a mestranda [S] e os professores [P1] e [P2], integrantes da banca do exame de qualificação de sua dissertação de mestrado.

A mestranda [S] é engenheira agrônoma e trabalha com pequenos agricultores para a recuperação de áreas degradadas. Desde criança, [S] participou de práticas de leitura em diferentes gêneros discursivos, tanto em contexto escolar quanto familiar. Foi aluna de escola pública no Ensino Fundamental e cursou o Ensino Médio em um colégio público considerado de excelente qualidade de ensino e de difícil ingresso pela alta concorrência para suas vagas. Ingressou em duas universidades públicas e, depois de cursar uma delas, formou-se com mérito a prêmios por estar entre os "dez melhores alunos durante todos os cinco anos de graduação", como afirmou em entrevista. Ao longo de sua graduação, produziu muitos textos para as disciplinas, como projetos de pesquisa e relatórios de laboratórios, e também teve dois projetos de iniciação científica aprovados pela Capes. Antes de chegar ao mestrado, fez ainda um curso de especialização em uma das mais renomadas universidades públicas do País. Para ingressar no mestrado, realizou exames escritos e submeteu-se a entrevistas, classificando-se em $2^{\circ}$ lugar. Em relação aos letramentos acadêmicos durante o mestrado, [S] cursou as disciplinas "Seminário I" e "Seminário II", nas quais assistiu a aulas de metodologia científica e estruturação de textos de alguns gêneros acadêmicos, como resumos para congressos e artigos para publicação em periódicos científicos. Também teve um painel exposto em um congresso nos Estados Unidos da América e um artigo sobre agricultura e áreas degradadas publicado em uma revista científica dirigida tanto a pesquisadores acadêmicos como a profissionais da área.

Considerando a história de letramento da mestranda [S], a discussão aqui proposta sobre a história do texto de sua dissertação de mestrado se concentra sobre a seção da Introdução de seu trabalho. Tem-se como objetivo investigar alguns indícios discursivos capazes de construir reflexões sobre os modos como a mestranda vai (re)significando algumas práticas acadêmico-científicas de escrita e se (re) posicionando como um sujeito discursivo a partir do próprio processo dialógico - e, 
portanto, de negociação - que ocorreu durante o evento do exame de qualificação e segundo as relações de poder ali constituídas. Segundo a concepção bakhtiniana (BAKHTIN/VOLOSHINOV, 2006), os sentidos são construídos e reconstruídos em meio à atividade dialógica da linguagem e, portanto, em meio ao próprio processo de enunciação, segundo o tema, o contexto/situação e os interlocutores. Embora o que se tem para dizer (o tema), seja pela escrita ou pela oralidade, apoie-se em alguma estabilidade da significação para não perder o vínculo com o que precede (já falado/já dito) e o que segue (a construir sentido), a significação pertence a um elemento ou a um conjunto de elementos verbais e não verbais em sua relação com o todo, isto é, com a enunciação. Assim, o sentido de um enunciado (falado ou escrito) só obtém acabamento na réplica que provoca, ou seja, na atitude responsiva (BAKHTIN, 2003, p. 289-326), pois a significação não está em si mesma, mas em "um potencial, uma possibilidade de significar no interior de um tema concreto" (BAKHTIN/VOLOSHINOV, 2006, p. 134, grifo do autor). Logo, a produção de sentidos não é um processo autônomo, totalmente controlado, e ocorre diante de uma situação concreta de enunciação e responsividade ativa, segundo o contexto e o lugar social e histórico que os sujeitos ocupam.

Desse modo, a significação será aqui tomada segundo seu caráter dialógico de construção de sentidos e, nesse processo de construção e reconstrução de sentidos, os sujeitos discursivos se posicionam e se reposicionam diante de suas próprias escolhas e de seus interlocutores:

Compreender a enunciação de outrem significa orientar-se em relação a ela, encontrar o seu lugar adequado no contexto correspondente. A cada palavra da enunciação que estamos em processo de compreender, fazemos corresponder uma série de palavras nossas, formando uma réplica. Quanto mais numerosas e substanciais forem, mais profunda e real é a nossa compreensão.

[...]. A compreensão é uma forma de diálogo; ela está para a enunciação assim como uma réplica está para a outra no diálogo. Compreender é opor a palavra do locutor uma contrapalavra. [...] a significação [...] só se realiza no processo de compreensão ativa e responsiva. A significação não está na palavra nem na alma do falante, assim como também não está na alma do interlocutor. Ela é o efeito da interação do locutor e do receptor produzido através do material de um determinado complexo sonoro. É como uma faísca elétrica que só se produz quando há contato dos dois polos opostos.

[...] A mudança de significação é sempre, no final das contas, uma reavaliação: o deslocamento de uma palavra determinada de um contexto apreciativo para outro (BAKHTIN/ VOLOSHINOV, 2006, p. 135-138, grifos do autor).

Para o autor, a reavaliação/ressignificação é resultante do que denominou como "alargamento do horizonte apreciativo", ou seja, "uma nova significação se descobre na antiga e através da antiga, mas a fim de entrar em contradição com ela e de reconstruí-la" (BAKHTIN/VOLOSHINOV, 2006, p. 139). Dessa maneira, 
o presente trabalho considera que o diálogo estabelecido entre [S] e os professores da banca do exame de qualificação construiu uma negociação dialógica que possibilitou um "alargamento do horizonte apreciativo" em relação às práticas letradas ali discutidas e, desse alargamento, a mestranda foi (re)significando as práticas acadêmico-científicas de escrita e se (re)posicionando. A partir disso, o trabalho de análise se insere num contexto maior de preocupação sobre a integração dos alunos a práticas letradas acadêmicas e ao modo como as pesquisas, na perspectiva aqui considerada sobre Letramentos Acadêmicos, podem contribuir para a compreensão e, consequentemente, para os processos de ensino e aprendizagem dessas práticas.

\section{0 exame de qualificação de mestrado como evento de letramento e suas práticas letradas}

Os letramentos são processos ideológicos e não se constituem por meio de um sistema universal, autônomo e independente da cultura (STREET, 2001, 2003, 2006), mas a partir de sentidos e usos situados, ligados tanto a contextos mais amplos de compreensão e concepções sobre a linguagem escrita quanto a contextos locais. O conceito de contexto está aqui relacionado com as discussões propostas por Street $(2001,2003,2006)$ sobre letramento autônomo e ideológico e sua relação com o conceito de modelo de letramentos acadêmicos (LEA; STREET, 1998, 2006), para considerar mais elementos que não apenas aqueles fornecidos pelo texto da mestranda e a partir de um recorte muito específico do contexto em torno do texto, tendo em vista o processo dialógico durante o exame de qualificação de mestrado aqui estudado. Logo, não é possível pensar em contexto como um cenário fixo em que são inseridas as práticas sociais. De acordo com Buzato, o "sentido de uma prática cultural qualquer só pode ser definido em relação ao contexto em que se insere" (2007, p. 48), então, contexto cultural também "só pode ser visto como algo constantemente redefinido e renegociado por meio das práticas, como um processo permanentemente aberto de construção, contestação e hibridização" (2007, p. 48). Isso significa que não se pode entender os contextos como imediatamente apreensíveis, permanentes e homogêneos, pois "são heterogêneos, dinâmicos e porosos" (2007, p. 50).

Certamente o exame de qualificação de mestrado pode ser compreendido como um fenômeno contextualizado local e remotamente, se for entendido como uma prática estabelecida segundo as regras locais de uma instituição acadêmica e, ao mesmo tempo, baseada em uma construção histórica que transpõe o local e se relaciona a práticas e contextos mais remotos no tempo e no espaço. Além disso, seus integrantes também pertencem ao contexto diretamente ligado ao exame de quali- 
ficação assim como a outros contextos. Por serem fortemente ligados a contextos de leitura e escrita, os exames de qualificações acadêmicas podem ser entendidos segundo o que Heath (1982) denominou como "eventos de letramento". Para a autora,

Um conceito-chave para o estudo empírico de maneiras de tomar sentido de fontes escritas nas comunidades é o de eventos de letramento: ocasiões em que a linguagem escrita é parte integrante da natureza das interações dos participantes e de seus processos e estratégias interpretativas. Eventos de letramento familiar para pré-escolares tradicionais são histórias de ninar, leitura de caixas de cereais, de sinais de trânsito e anúncios de televisão, e a interpretação de instruções para jogos e brinquedos. Nesses eventos de letramento, os participantes seguem regras socialmente estabelecidas para verbalizar o que sabem de e sobre o material escrito. Cada comunidade tem regras para interagir e compartilhar socialmente o conhecimento em eventos de letramento (HEATH, 1982, p. 50, tradução livre).

Prinsloo e Baynham também discutem o conceito de evento, mas de modo a ampliá-lo para as práticas letradas:

Eventos de letramento são frequentemente caracterizados por combinações de texto, conversa, distribuição de ação e tomada de turno na comunicação e interação, mas também incluem momentos de leitura solitária e escrita. [...] A importância do conceito de eventos de letramento é que ele incentiva o estudo empírico da leitura e da escrita como elas são usadas, respondidas e valorizadas em momentos particulares da atividade social identificável, chamando a atenção para a natureza social e variável de atos particulares ou usos da leitura e da escrita. O ponto de vista invocado de letramento não é como uma entidade única, mas um conjunto de práticas comunicativas e atitudes historicamente influenciadas por essas práticas (PRINSLOO; BAYNHAM, 2013, p. XXXI, tradução livre).

Os exames de qualificação de mestrado podem ser vistos como eventos contextualizados em que o texto escrito é apresentado aos professores da banca para discutirem não apenas os caminhos da pesquisa e sua coerência, mas a própria escrita contida naquela versão. $\mathrm{Na}$ instituição acadêmica em que os registros de dados ocorreram, esse evento é um momento preliminar ao evento da defesa, quando, por um tempo máximo de vinte minutos e com recursos de projeção de textos escritos e imagens em uma tela, os mestrandos fazem uma apresentação oral de suas pesquisas para um comitê de professores doutores e um auditório composto por outros professores e alunos de graduação e pós-graduação, ou seja, não é um evento reservado, mas aberto e assistido por muitas pessoas. Nesse evento, a dissertação é apresentada a um comitê formado por três professores, dos quais, um apenas preside a sessão e os outros dois fazem comentários orais sobre o texto que lhes foi previamente enviado e sobre o qual também deixaram apontamentos escritos. Desses dois professores arguidores, [P2], da mesma universidade em que [S] fez o mestrado, é especialista em ervas daninhas e pragas em plantas, enquanto [P3] é de uma instituição acadêmica externa e especialista na planta estudada pela mestranda. Por decisão própria, o professor orientador de [S] optou por não assistir 
à qualificação ${ }^{2}$, por isso, não há qualquer referência a ele durante a análise dos dados. Como protocolo de início ao exame, o professor presidente da banca de [S] fez um rápido discurso em que apresentou os outros dois professores e caracterizou o evento de qualificação como uma "pré-defesa".

\section{"Introdução" para a mestranda e para os professores: posicionamento, interlocução e relações de poder}

A dissertação de mestrado de [S] resultou de um experimento conduzido em laboratório por aproximadamente seis meses, cultivando várias amostras de duas espécies da planta [PL] em vários recipientes, os quais foram submetidos a diferentes umidades de solo e temperaturas, pois seu objetivo era investigar a incidência da doença [D] naquela planta, segundo variações de temperatura climática e umidade do solo. De todo o texto, a análise aqui pretendida se concentra em fragmentos do processo dialógico sobre a primeira página da Introdução do trabalho de [S] e toma como ponto de partida os posicionamentos sociais e históricos ocupados pelos sujeitos e as relações de poder estabelecidas durante o exame de qualificação. $\mathrm{O}$ objetivo é investigar a "história do texto" da dissertação de [S] em relação à sua Introdução, segundo três categorias de análise: (i) posicionamentos, (ii) interlocuções e (iii) relações de poder.

A partir das observações feitas pelos professores e considerando as escolhas linguístico-discursivas feitas por [S] para a escrita de sua dissertação, também proponho uma divisão que identifico como: (a) Grande Tema (GT), para reportar a um universo mais amplo da discussão que envolve a pesquisa; e (b) Tema Específico (TE), para identificar especificamente ao tópico que é objetivo principal de discussão e análise. No caso da dissertação escrita por [S], o GT refere-se a "ambiente e mudanças climáticas" e o TE, à doença [D] afetando especificamente a [PL], segundo determinadas condições de umidade e temperatura. Para fazer a escrita da Introdução, [S] escolheu dispor diversas informações sobre mudanças climáticas, ações antrópicas, doenças, alimentos e fome, como se pode observar na primeira página da Introdução, reproduzida a seguir: 


\section{Introdução}

[1 ${ }^{\circ}$ p] Com o aumento da população mundial, na busca contínua por alimentos, a humanidade vem continuamente transformando os ecossistemas naturais em agroecossistemas. Há algumas décadas eram muito escassos os conhecimentos científicos sobre o ambiente e as preocupações com os reflexos das mudanças do uso do solo e com a queima dos combustíveis fósseis nas alterações climáticas globais.

[ $\left.2^{\circ} p\right]$ As atividades antrópicas estão alterando as concentrações de gases do efeito estufa na atmosfera, resultando em mudanças no clima. Essa ação antrópica foi intensificada após a Revolução Industrial, nos séculos XVIII e XIX, passando pela Revolução Verde, no século $\mathrm{XX}$, onde houve a inserção de altas tecnologias para o aumento nas produções agrícolas, aumentando assim a emissão dos gases na atmosfera devido ao uso de recursos naturais pelo homem.

$\left[3^{o} p\right]$ Um dos principais gases do efeito estufa é o gás carbônico $\left(\mathrm{CO}_{2}\right)$, que merece destaque por absorver a radiação infravermelha, causando o aumento da temperatura. Segundo o Painel Intergovernamental de Mudanças Climáticas (IPCC), a concentração de gás carbônico aumentou $35 \%$ nos últimos 150 anos.

$\left[4^{\circ}\right.$ p] Esse aumento na retenção de radiação, resultando em elevação da temperatura média da superfície do planeta é denominado aquecimento global.

$\left[5^{\circ} p\right]$ Somente nas últimas décadas, devido às evidências, os cientistas perceberam os impactos gerados por esse aquecimento na distribuição de chuvas, nas oscilações de temperatura e no nível do mar, nas alterações de produções de alimentos e também no aparecimento e ressurgimento de doenças dos reinos vegetal e animal.

$\left[6^{o} p\right]$ O mais recente relatório do IPCC prevê que a produção de alimentos em todo o mundo pode sofrer um impacto dramático nas próximas décadas por conta das mudanças climáticas provocadas pelo aquecimento global. Segundo os cientistas do painel, o aumento da temperatura ameaça o cultivo de várias plantas agrícolas e pode piorar o já grave problema da fome em partes mais vulneráveis do planeta. Países pobres da África e da Ásia seriam os mais afetados, mas grandes produtores agrícolas, como o Brasil, também sentiriam os efeitos, já na próxima década $\left(\mathrm{XXXXX}^{3}\right.$ et al., 2008).

Os professores da banca criticaram muito essa primeira página da dissertação da mestranda, referindo-se à delimitação e à abrangência do tema, assim como à concisão e à pertinência de muitas informações. Nos fragmentos a seguir, baseados tanto nas notas escritas sobre a dissertação de [S] quanto nos comentários orais feitos durante o exame de qualificação, há exemplos dessas críticas: 
Comentários escritos feitos por [P2]:

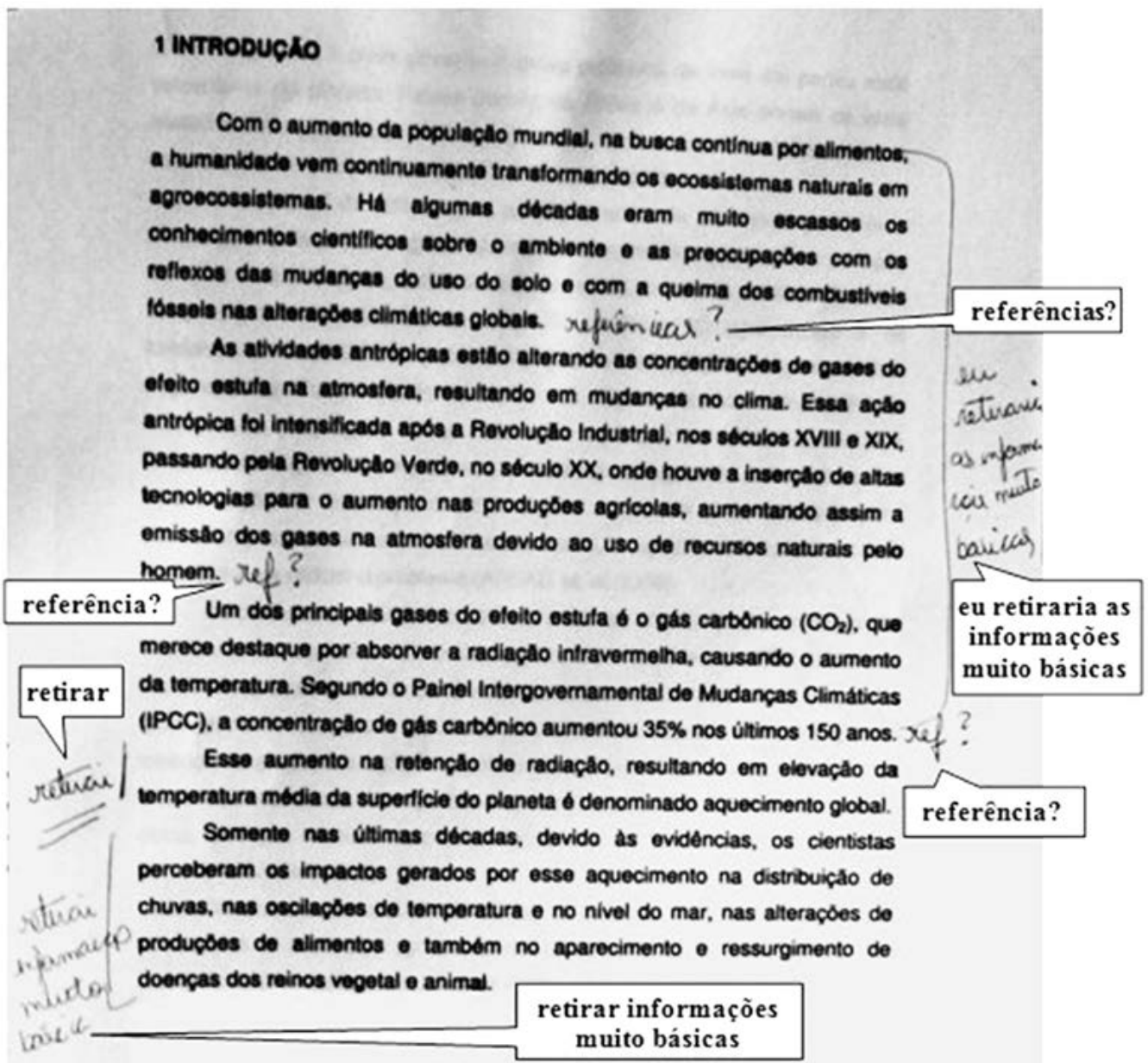

Comentários orais de [P2] durante a qualificação:

“[...] Na introdução, achei que ficou faltando a parte mais importante que é como mudanças climáticas podem influenciar na civilização, na idade das doenças. [...] Não precisa contar desde a Revolução industrial... tudo isso a gente já sabe...então, dá pra fazer uma leitura um pouco mais concisa disso tudo, do que é realmente importante. [...] Na minha avaliação, a sua introdução não introduz o tema; tem apenas quatro laudas sobre $[P L] . O[P L]$ é o mais importante. [...] Eu achei muito fragmentada... é difícil de ler. Falta uma linha de desenvolvimento" (grifos nossos). 
Comentário escrito feito por [P2] no final da Introdução:

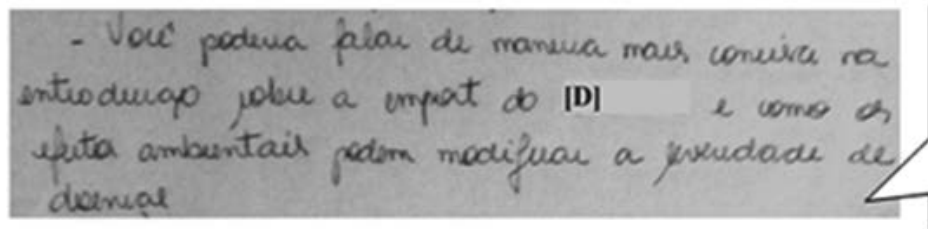

Você poderia falar de maneira mais concisa na introdução sobre a importância da [D] $e$ como os efeitos ambientais podem modificar a severidade de doenças

Comentários orais de [P3] durante a qualificação:

"A introdução é feita para objetivar os objetivos do trabalho. A sua introdução traz elementos desnecessários, como a ênfase desnecessária ao $\mathrm{CO}_{2}[\ldots]$ não precisa ficar explicando sobre mudança climática" (grifos nossos).

Comentários escritos feitos por [P3]:

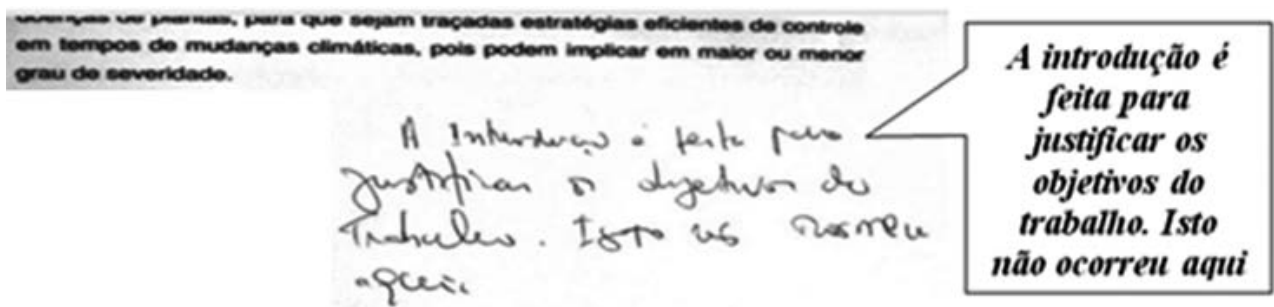

Comentário oral de [S] durante a qualificação:

“Então, tira um pouco de clima?" (grifos nossos).

O lugar social e histórico ocupado pelos professores da banca ao participarem do exame de qualificação de [S] é o de quem demanda a responsabilidade ao que eles mesmos, ao longo do evento, denominaram como "comunicação científica", numa referência à necessidade de clareza sobre a linguagem utilizada para descrever a pesquisa. Considerando, a partir disso, que o diálogo estabelecido com [S] tem o objetivo tanto de questioná-la sobre a pesquisa quanto de incidir sobre sua prática de escrita da dissertação, a professora [P2], especialista em ervas daninhas, iniciou suas indagações orais sobre a Introdução, referindo-se (a) ao caráter prescindível de "informações muito básicas"; (b) à necessidade de retirar as "informações muito básicas"; e (c) à falta de referências bibliográficas ${ }^{4}$ sobre os dizeres em praticamente todos os parágrafos da Introdução.

A referência de [P2] à "fragmentação" e à falta de "uma linha de desenvolvimento" é uma tentativa de levar [S] a compreender que a exposição de muitas informações, com ou sem referências explícitas, não compõe um todo articulado. Ao mesmo tempo em que questiona e cobra a falta de referências, a professora também faz notas sobre os mesmos trechos referindo-se à necessidade de [S] "retirar as informações básicas" e "falar de maneira mais concisa sobre a importância da doença 
[D] e como os efeitos ambientais podem modificar a severidade das doenças". O que [P2] aponta como falta de concisão e "ideias básicas" são, por um lado, indícios sobre o modo como busca esclarecer sua visão sobre os limites entre o GT e o TE e, por outro, marcas linguístico-discursivas que refletem os sentidos que constrói sobre essa prática escrita. Assim, [P2] sinaliza que aquela escrita da Introdução - com aquelas informações e naquele modo de dizer - não pode ser aceita porque não está dentro dos parâmetros que conhece para o gênero, ou seja, não contém referências na maioria dos parágrafos, não possui relações claras entre o GT e o TE e, por fim, não deixa claro o foco da pesquisa. Todo o processo de fragmentação, de falta de uma linha de desenvolvimento, de (não) relação entre os tópicos, de prolixidade e de (não) focalização no tema da pesquisa ao qual [P2] se refere pode ser mais bem compreendido se recuperarmos o esquema de desenvolvimento dos tópicos da primeira página da Introdução:

\begin{tabular}{|c|c|}
\hline $1^{\circ} \mathrm{p}$ & $\begin{array}{l}\text { Aumento da população mundial }+ \text { alimentos }+ \text { ambiente }+ \text { uso do solo + queima de } \\
\text { combustíveis fósseis + alterações climáticas globais }\end{array}$ \\
\hline $2^{\circ} \mathrm{p}$ & $\begin{array}{l}\text { Atividades antrópicas + alteração de gases estufa + mudança no clima + Revolução } \\
\text { Industrial + Revolução Verde + aumento nas produções agrícolas }\end{array}$ \\
\hline $3^{\circ} p$ & Gás carbônico + aumento da temperatura + dados do IPCC \\
\hline $4^{\circ} \mathrm{p}$ & Retenção da radiação + temperatura média do planeta + aquecimento global \\
\hline $5^{\circ} \mathrm{p}$ & $\begin{array}{l}\text { Impactos do aquecimento global + distribuição de chuvas + oscilações de temperatura e } \\
\text { nível do mar + produção de alimentos + aparecimento e ressurgimento de doenças do } \\
\text { reino animal e vegetal }\end{array}$ \\
\hline $6^{\circ} \mathrm{p}$ & $\begin{array}{l}\text { Impacto dramático na produção de alimentos + mudanças climáticas + aquecimento global } \\
\text { + plantas agrícolas + fome + efeitos do aquecimento global para África, Ásia e Brasil }\end{array}$ \\
\hline
\end{tabular}

Como observamos, são muitos assuntos diferentes, não claramente interligados e sem explicitação da relação entre o GT e o TE. Com outras formas de fazer esses apontamentos, [P3], especialista na planta estudada por [S], também insiste nessa condição de escolhas pouco significativas quando diz que a Introdução "traz elementos desnecessários, como a ênfase desnecessária ao $\mathrm{CO}_{2}$ ”. Para justificar sua discordância e recusa das escolhas linguístico-discursivas de [S], o professor busca formular um conceito sobre a Introdução, explicando que "é feita para justificar os objetivos do trabalho" ou "para objetivar os objetivos do trabalho". Por mais que seja confusa para a mestranda - porque se situa em limites de conceitos cruzados entre Introdução e Objetivos -, a concepção de [P3] se aproxima de [P2] por também sinalizar a relação pouco clara e pertinente entre o GT e o TE. As marcas lin- 
guísticas dos comentários orais e escritos de [P2] e [P3] sobre a dissertação escrita apontam que os sentidos que ambos constroem sobre essa prática escrita partem de concepções diferentes de [S], para quem, as escolhas linguístico-discursivas eram necessárias e ligadas ao seu próprio lugar social e histórico de aluna de mestrado e também de engenheira agrônoma, como veremos a seguir.

Em entrevista/conversa ${ }^{5}$, após o exame de qualificação, perguntei a [S] sobre os questionamentos dos professores em relação à Introdução. Ao fazer suas explicações, a mestranda traz à tona o porquê de suas escolhas, considerando não apenas o valor das informações para a apresentação das pesquisas, mas a quem e como estava interessada em se dirigir, ou seja, a quais interlocutores quis privilegiar em seu processo de escrita. Primeiramente, [S] respondeu à pergunta sobre sua escolha em falar sobre "mudanças climáticas" e, depois, explicou a relação dessa escolha com os propósitos de sua pesquisa e com seus procedimentos metodológicos:

[E]: Por que, na sua Introdução, você escreveu sobre "mudanças climáticas"?

[S]: Porque em 2009, teve uma epidemia dessa doença muito grande e teve muitos danos na lavoura de [P] [...] Porque 2009 foi um ano muito diferente, entendeu? Ele foi muito quente e muito chuvoso... então, isso ocorreu por quê? Por causa da ocorrência das mudanças climáticas. Esse verão, por exemplo, ocorreram muitas.... choveu bastante, mas as chuvas foram muito mais concentradas do que no ano passado, por exemplo. Então, nós não temos mais um ano igual ao outro. Cada ano tem sido diferente pra agricultura. Por quê? Porque o ambiente está mudando...

[E]: E daí... qual a relação disso com a doença [D]?

[S]: Essas mudanças que estão ocorrendo no clima estão influenciando a ocorrência da doença [D]. Em 2009, foi horrível, péssimo. Em 2010, já não foi.

[E]: E qual a relação dessas mudanças climáticas com a experiência que você quis realizar em laboratório, com os dados que você coletou?

[S]: Então... o que é que eu fiz? [...] interceptei a doença em diferentes períodos de molhamento [...] como se fosse a umidade do campo, entendeu? Com mais umidade e com menos umidade, para ver se ocorria mais ou menos doença [...] e maiores temperaturas e menores temperaturas (grifos nossos).

$\mathrm{Na}$ entrevista, [S] demonstra que fez escolhas para o texto da Introdução em decorrência do que entendeu como necessidade tanto para contextualizar a própria pesquisa quanto para vinculá-la ao mundo real. No processo dialógico estabelecido por essas críticas, [S] passa a questionar que suas escolhas também dialogavam com sua profissão de engenheira agrônoma, cuja preocupação, no dia a dia, envolve a recuperação de áreas degradadas de pequenos agricultores, como pode ser visto no trecho a seguir: 
[E]: Qual a relação dessas temperaturas, dessa pesquisa de laboratório com esse mundo externo das mudanças climáticas... com os exemplos, com os conceitos que você trouxe da mudança climática lá na Introdução? [...] Talvez você ache que para as pessoas isso seja mais óbvio? É óbvio falar de mudanças climáticas afetando tudo?

[S]: É porque é assim... o meu mestrado é em Agricultura e Ambiente, então, eu quis falar também das mudanças climáticas porque é como se fosse, assim, [...] o meu trabalho de agricultura ser um apelo ambiental. Só que hoje, depois da minha qualificação, eu percebo que não precisava disso. Se eu tivesse feito um estudo de doença em diferentes ambientes, também está dentro do tema. [...] (grifos nossos).

A mestranda [S] faz suas escolhas também em função de sua necessidade de diálogo com o mundo externo ao da pesquisa e diretamente relacionado com sua formação e trabalho com pequenos agricultores em relação à recuperação de áreas desmatadas. O diálogo com esses interlocutores é fortemente amplificado, mas, sob as críticas, também é reconsiderado quando afirma que percebe "que não precisava disso". Desencadeia-se, assim, um reposicionamento social e histórico de [S] sobre as próprias escolhas linguístico-discursivas para a Introdução e sua reconstrução de sentidos para essa prática letrada considerando:

a) o seu lugar social e histórico ao querer dialogar com o mundo ao seu redor como engenheira que tem como interlocutores também os agricultores;

b) os lugares sociais e históricos de [P2] e [P3] ao sinalizarem que o diálogo deve privilegiar seu lugar de pesquisadora que tem interlocutores acadêmico-científicos para sua "comunicação científica".

Tudo isso leva a considerar que, por um lado, em qualquer campo de investigação, os enunciados jamais são neutros, exatamente porque partem de sujeitos que fazem escolhas linguístico-discursivas e, por outro, se constituem na relação de alteridade com o outro (outros sujeitos; outros enunciados). Os sujeitos se posicionam para escrever e, de um modo ou de outro, têm suas escolhas guiadas segundo um processo dialógico que mantêm com os lugares sociais e históricos que ocupam dentro e fora da academia e um processo de alteridade que constitui o "eu" no "outro". Esse caráter discursivo do diálogo estabelecido entre [S] e os professores da banca, em meio a determinadas relações de poder ali existentes, acabam reconfigurando os significados dessa prática letrada para [S] à medida que, antes da qualificação, a mestranda busca compreender o que seria ou não pertinente segundo seu objetivo de construir sentidos considerando as relações sociais e as interlocuções que estabelece dentro e fora do mundo acadêmico, com outros grupos sociais, como é o caso dos pequenos agricultores. Mas, durante e após a qualificação, [S] busca compreender o que seria ou não pertinente de acordo com seu objetivo de construir sentidos 
considerando fundamentalmente as interlocuções que se estabelecem dentro do mundo acadêmico-científico.

Entende-se, pois, que enquanto as escolhas de [S] consideram inicialmente "o que" dizer, os professores estão sinalizando a necessidade de atentar para o movimento concomitante entre "o que", "como" e de "onde" dizer, não apenas em relação às costuras linguísticas necessárias à passagem de um tópico ao outro, mas, principalmente, em relação ao lugar de pesquisadora que deve desenhar seu objeto de estudo, segundo um gênero discursivo que possui uma característica temática na relação entre GT e TE e se liga à necessidade de compreensão acadêmico-científica. Os apontamentos feitos pelos professores da banca representam um modo de sinalizar que:

a) os tópicos escolhidos para fazer a Introdução do tema e apresentar a pesquisa não são escolhas tão livres, como pode ter ocorrido em outras situações de escrita e interlocução;

b) essas escolhas precisam ser justificadas pelo lugar discursivo ocupado pela pesquisadora em sua relação com a pesquisa e com seus interlocutores específicos e, não, por uma relação entre o sujeito e alguma coisa do mundo externo à pesquisa acadêmico-científica;

c) os professores da banca são interlocutores críticos e posicionados verticalmente nas relações de poder ali existentes. Embora questionem a mestranda a partir de um ponto de vista que incide sobre os modelos de habilidades e de socialização do discurso acadêmico, como se fosse apenas uma questão de codificar melhor a escrita e demonstrar conhecimento acadêmico, acabam, na verdade, exigindo respostas e atitudes de um sujeito discursivo familiarizado com os contextos e condições das práticas letradas acadêmicas e com seu lugar de pesquisador;

d) as escolhas e o lugar social e histórico de pesquisadora fazem parte de um processo de construção de sentidos a partir da alteridade que se desenvolve em meio à negociação dialógica.

Todas essas reflexões levam à ideia de que a integração dos sujeitos a práticas letradas acadêmicas seria, essencialmente, de ordem discursiva. De acordo com Pasquotte-Vieira (2014, p. 217), essa integração é concebida como um movimento constituído pela alteridade a partir do trabalho mútuo dos sujeitos sobre a prática escrita em meio a um processo de construção de sentidos, posicionamentos discursivos e relações de poder. Por esse ponto de vista discursivo, o conceito de integração caminha no sentido contrário ao da ideia de que seria apenas o efeito de um trabalho individual, de um esforço particular, de uma competência própria 
de um sujeito cognitivo, hábil, socializado com o discurso acadêmico e com as características de um gênero discursivo. A integração de [S] às práticas escritas de sua dissertação é desencadeada em meio à negociação dialógica que ocorre durante seu exame de qualificação, a partir de um processo mútuo e contínuo de construções de sentidos e posicionamentos e envolve as concepções da mestranda e dos professores sobre linguagem, escrita, gêneros e ciência - ou o que os professores da banca designam como "comunicação científica". Isso leva a conceber a integração dos sujeitos a práticas letradas acadêmicas segundo um processo dinâmico de alteridade que é permanentemente aberto e constantemente redefinido e renegociado em meio aos interlocutores, às relações de poder e ao contexto em que se inserem.

\section{Considerações finais}

A reconstrução da "história do texto" da Introdução da dissertação da mestranda [S] a partir do processo dialógico construído durante o exame de qualificação aponta para importantes reflexões sobre a constituição de um sujeito discursivo em meio a determinadas relações interlocutivas e de poder. Ao considerar apenas o texto da mestranda como foco de análise, certamente, chegar-se-á a indícios capazes de refletir, por exemplo, sobre questões de coerência e coesão textual, como aquelas apontadas na Introdução pelos professores da banca do exame de qualificação. Mas, ao se refletir sobre o material linguístico em meio aos elementos etnográfico-discursivos, aqui considerados por meio dos diálogos em torno do texto, percebe-se que um aspecto fundamental a ser considerado para a escrita acadêmico-científica de estudantes-pesquisadores-escritores é que os movimentos de redução ou expansão da escrita apenas podem ser compreendidos em meio ao processo de alteridade em que os sujeitos se envolvem para a construção de sentidos e posicionamentos sociais e históricos.

Todo o processo de significação e ressignificação da prática acadêmica letrada aqui discutida, envolvendo os posicionamentos e reposicionamentos de [S], ocorreu intrinsecamente ao processo de alteridade que se estabeleceu no conflito dialógico entre a mestranda e seus professores da banca do exame de qualificação. $\mathrm{O}$ termo "conflito" não é aqui tomado em um sentido negativo, mas de modo coerente com tudo o que foi discutido sobre as relações de poder específicas dessas práticas letradas nessa esfera. Esse conflito ocorre à medida que o texto, como enunciação dialógica, apenas terá seu acabamento e construção de sentidos quando circula para outros interlocutores e, no processo de alteridade, é negociado o que precisa ser explicitado ou excluído. Certamente, todo o conflito construído no contexto dialógico que provocou os questionamentos sobre a dissertação de [S] representou 
um importante processo de negociação sobre sua prática escrita que resultou em ressignificações e reposicionamentos.

O princípio linguístico-discursivo de construção de sentidos leva a compreender a responsividade como constitutiva da alteridade dos sujeitos, ou seja, no processo dialógico entre os interlocutores, o "eu" se constitui a partir do "outro". Dessa maneira, $[\mathrm{S}]$ vai se posicionando no diálogo estabelecido com os professores da banca enquanto questionada em relação às suas escolhas, as quais estão fundamentalmente relacionadas com os diferentes lugares que [S] ocupa como um sujeito discursivo, situado social e historicamente e em constante processo de construção - no caso da mestranda, como aluna/mestranda/pesquisadora. Nesse processo, os significados construídos nos diálogos entre [S] e os professores se estendem ao plano discursivo em que consideramos: quem diz, por que diz, quando diz, de onde/de qual lugar social e histórico diz, como diz, em qual contexto/em que situação, com quais intenções/objetivos, para quais interlocutores, em meio a quais relações de poder. Assim, embora "o quê" escrever seja inicialmente construído com o decorrer dos experimentos e da investigação científica, "o quê", "como" e "de onde" escrever precisam ser discutidos não apenas para compreensão do gênero, mas, também, para a própria compreensão do lugar a ser ocupado por um sujeito discursivo pesquisador-escritor diante de interlocutores específicos e de relações de poder. No caso da banca de exame de qualificação da dissertação, os membros terão responsabilidade científica sobre aquilo que aprovam. De um modo geral, essa interlocução também ocorre tanto em relação à instituição a que o estudante pertence quanto à própria comunidade científica local e global com as quais ele e sua instituição interagem.

Nesse sentido, depreende-se que o processo de integração a práticas letradas acadêmicas está também relacionado a uma instância anterior à do exame de qualificação: a da orientação. [S] foi para o exame de qualificação sem que seu professor-orientador tivesse lido e discutido com a mestranda sua dissertação. Segundo a mestranda, ele a orientou durante a realização dos procedimentos laboratoriais da investigação, mas ao fim da produção dos registros, ela permaneceu sem qualquer orientação para a escrita. Os próprios professores da banca de [S] apontaram para questões que poderiam ter sido trabalhadas se a mestranda tivesse tido a negociação com o seu orientador. O professor [P3], em seu modo de expressar a importância da negociação, elabora uma crítica a isso, quando, durante o exame, diz a [S]: "seu orientador tem uma linha de conduta que a gente tem de respeitar, mas talvez a sua falha foi, por exemplo, não ter procurado mais gente pra suprir essa opinião [...]". [P3] se refere à "opinião" de [S] ao longo da dissertação e à própria necessidade de diálogo sobre os caminhos da escrita. Nesse momento, podemos 
dizer que esse professor nos leva a um ponto essencial da negociação dialógica: a importância da orientação/da interlocução no processo de integração dos sujeitos a práticas letradas acadêmicas à medida que, no processo de alteridade, tem-se o trabalho mútuo dos sujeitos sobre a construção de sentidos e, ao mesmo tempo, sobre os movimentos de redução ou expansão do texto. Ou seja, por um lado, os professores da banca de qualificação, pelo modo como criticam e apontam os problemas contidos na dissertação da mestranda, nos aproximam do discurso do déficit. Mas, por outro, também apontam para a integração da mestranda à medida que nos conduzem a questões sobre a circulação do texto, os interlocutores, as relações de poder e a construção de sentidos no processo dialógico.

Em todo o processo de diálogo, os professores tentam integrá-la, inseri-la em práticas letradas acadêmicas segundo o que constroem de sentido para elas. À medida que o diálogo, a discussão e a negociação sobre a escrita ocorrem, os significados para as práticas se reconstroem e, simultaneamente, os posicionamentos discursivos também. Dessa maneira, a escrita da dissertação de mestrado pode ser vista como um processo de coenunciação construído por meio do diálogo com os "outros", ao mesmo tempo, que culmina na autoria de um sujeito discursivo que, de seus (re)posicionamentos sociais e históricos, faz suas escolhas linguístico-discursivas para (re)escrever. Assim, as práticas letradas situadas emergem bem mais de sujeitos discursivos do ponto de vista bakhtiniano do que de sujeitos cuja meta é apenas o desenvolvimento de habilidades ou a socialização do saber - até porque a história de letramento de [S] a aproxima de habilidades e de socialização acadêmica e, mesmo assim, a mestranda recebeu muitas críticas em sua escrita da dissertação. Por esse prisma, seria possível deslocar o discurso do déficit e da crise da escrita para uma perspectiva que toma os letramentos acadêmicos como práticas letradas situadas socioculturalmente e, por isso, sempre demandam processos de ensino e aprendizagem segundo uma perspectiva discursiva e dialógica. Como já foi dito, essa perspectiva permite conceber a integração dos sujeitos a práticas letradas acadêmicas segundo um processo permanentemente aberto e dinâmico de alteridade em meio aos interlocutores, às relações de poder e ao contexto em que as práticas se inserem. 


\section{Academic Literacies and Discursive Subject: dialogy, alterity and negotiation on writing}

\section{Abstract}

As a case study, this work reflects on the integration of the subjects in academic literacy practices, considering the dialogues between a master student and the professors of the Qualifying Committee of her dissertation. The goal is to investigate the ways with which the student was building her (re)meaning on academic-scientific practices of writing and her (re)placements as a discursive subject into that dialogical process - and of negotiation - around the Introduction of her dissertation. This study is founded, on the one hand, on bakhtinian linguistic-discursive perspective and, on the other hand, on contributions from the Academic Literacies studies. From this, it builds itself a linguistic ethnographic perspective, based more specifically on what Lillis (2008) has understood as "text history", that is, a theoretical and methodological framework for the simultaneous analysis of the text and other data from the situated context around the text. This analysis seeks to contribute with understanding to academic practices of writing and its process of meanings for the subjects.

Keywords: Academic Literacies. Academic Genre. Academic Writing. Scientific Writing. Linguistic Ethnography.

\section{Notas}

1 Artigo baseado nas investigações que compõem a tese de Doutorado da autora (PASQUOTTE-VIEIRA, 2014).

2 No campus em que esta investigação ocorreu, é prática comum aos professores-orientadores participarem dos exames de qualificação de seus orientandos. No caso de [S], após cumprimentar os professores da banca e a mestranda, o orientador se ausentou da sala onde o exame ocorreu, sem se justificar. Durante a entrevista a mim concedida após o exame de qualificação, [S] afirmou que essa postura de omissão se estendeu também em relação à própria orientação da dissertação à medida que o orientador não fez leituras, críticas ou sugestões.

3 Código utilizado para manter sigilo da referência.

4 Neste artigo, não tenho como objetivo a análise de questões relacionadas às referências bibliográficas. Essa discussão pode ser encontrada em Pasquotte-Vieira ( 2014), especialmente, no Capítulo 4.

5 A entrevista não foi estruturada com perguntas preestabelecidas e se desencadeou semelhante a uma conversa sobre o exame e a dissertação. Sinalizei com [E] minhas perguntas e com [S], as respostas da mestranda.

\section{Referências}

BAKHTIN, Mikhail (Voloshinov). Marxismo e filosofia da linguagem. 12. ed. Tradução M. Lahud e Yara F. Vieira. São Paulo: Hucitec, 2006 [1929-1930].

BAKHTIN, Mikhail. Estética da criação verbal. 4. ed. Tradução Paulo Bezerra. São Paulo: Martins Fontes, 2003 [1952-1953]. 
BUZATO, Marcelo. Desafios empírico-metodológicos para a pesquisa em letramentos digitais. Trabalhos em Linguística Aplicada, Campinas, v. 46, n. 1, p. 45-62, jan./jun. 2007.

HEATH, Shirley B. What no bedtime story means: Narrative skills at home and school. Language in society, Printed in the United States of America, Cambridge, Cambridge University Press, II, v. 11, n. 1, p. 49-76, Apr. 1982.

LEA, Mary R.; STREET, Brian V. The 'Academic Literacies' Model: Theory and Applications. Theory into Practice Fall, [S. 1.], v. 45, n. 4, p. 368 -377. 2006.

. Student Writing in Higher Education: an Academic Literacies Approach. Studies in Higher Education, [S. l.], v. 23, n. 2, p. 157-173, June 1998.

LILLIS, Theresa M. Ethnography as Method, Methodology, and "Deep Theorizing": Closing the Gap Between Text and Context in Academic Writing Research. Written Communication, University of Minnesota, Twin Cities, USA, v. 25, n. 3, p. 353-388, July 2008. Disponível em: <http:// wcx.sagepub.com/cgi/content/abstract/25/3/353>. Acesso em: 5 jul. 2012.

"An "academic literacies" approach to student writing in higher education: drawing on Bakhtin to move from "critique" to "design". Language and Education, London, v. 17, n. 3, p. 192-207. 2003.

Whose 'Common Sense'? Essayist literacy and the institutional practice of mystery. In: JONES, C.; TURNER, J.; STREET, B. (Org.). Students writing in the university: cultural and epistemological issues. Amsterdam: John Benjamins, 1999. p. 127-140.

PASQUOTTE-VIEIRA, Eliane A. Letramentos Acadêmicos: (re)significações e (re)posicionamentos de sujeitos discursivos. 2014. 262 f. Tese (Doutorado em Linguística Aplicada) - Instituto de Estudos da Linguagem, Universidade Estadual de Campinas, Campinas, 2014.

PRINSLOO, Mastin; BAYNHAM, Mike. Editors' Introduction: Literacy Studies. In: PRINSLOO, Mastin; BAYNHAM, Mike (Org.). Literacy Studies: Great Divides and Situated Literacies. London: Sage Publications, 2013. p. XXIII-XXXV. v. 1.

RAMPTON, Ben et al. UK Linguistic Ethnography: A Discussion Paper, Unpublished, 2004. p. 1-24. Disponível em: <http://www.ling-ethnog.org.uk>. Acesso em: 9 mar. 2010.

STREET, Brian V. 'Academic Literacies approaches to Genre’? Revista Brasileira de Linguística Aplicada. Belo Horizonte, v. 10, n. 2, p. 347-361, June 2010.

. "Hidden" Features of Academic Paper Writing. Working Papers in Educational Linguistics. Philadelphia: UPenn, v. 24, n. 1, p. 1-17. 2009.

What's "new" in New Literacy Studies? Critical approaches to literacy in theory and practice. Current Issues in Comparative Education, Teachers College, Columbia University, v. 5, n. 2, p. 77-91, May 2003.

Introduction. In: STREET, Brian (Org.). Literacy and development - ethnographic perspectives. London: Routledge, 2001. p. 1-18. 